\title{
Associação entre caracteres e análise de trilha na seleção de progênies de meios-irmãos de Brachiaria ruziziensis ${ }^{1}$
}

\author{
Vanderley Borges ${ }^{2 *}$, Fausto Souza Sobrinho ${ }^{3}$,Francisco José da Silva Lédo ${ }^{3}$,Maurício Marini Kopp ${ }^{4}$
}

\section{RESUMO}

Associação alta entre peso de massa seca e peso de massa verde pode facilitar a seleção antecipada de genótipos superiores de B. ruziziensis. Objetivou-se neste estudo verificar as associações entre características morfo-agronômicas na seleção de genótipos de B. ruziziensis. O delineamento experimental foi o de blocos completos casualizados com duas repetições. Foram avaliadas as características altura e vigor das plantas, peso de massa verde e porcentagem de matéria seca da planta inteira, do caule e da folha, peso de massa seca da forragem total, de caule, e de folha e, relação entre produtividade de folha e caule de massa verde. As análises consistiram da estimação das correlações simples entre os caracteres e da análise de trilha considerando o peso de massa seca total como variável básica e as demais explicativas. Correlações mais elevadas foram observadas entre peso de massa seca e peso de massa verde, peso seco de caule e peso de massa verde e, peso seco de folhas e peso de massa verde. Pelos coeficientes de trilha, verificou-se que os efeitos diretos das diferentes variáveis explicativas sobre o peso de massa seca foram, em sua maioria, baixos. Os efeitos diretos mais relevantes sobre o peso de massa seca foram verificados via peso de massa verde, peso seco de caule e peso seco de folhas, indicando que o peso de massa verde viabiliza a seleção indireta para peso de massa seca.

Palavras-chaves: Correlação, seleção indireta, melhoramento de forrageiras.

\section{ABSTRACT}

\section{Association between traits and path analysis in half-sib progeny selection of Brachiaria ruziziensis}

High association between fresh and dry mass weight can facilitate early selection of superior genotypes of $B$. ruziziensis R. Germ. \& C.M. Evrard. The aim of this study was to verify the associations between traits in the selection of $B$. ruziziensis genotypes. The experiment was arranged in a complete randomized block design with two replications. The traits evaluated were height and vigor of plants; weight of fresh mass and percentage of dry matter of the whole plant, stem and leaf; dry mass weight of total herbage, stem, and leaf and the ratio between productivity of leaf and stem. Estimation of simple correlations and path analysis were performed considering the dry mass weight as the main variable. The correlations were mostly low, but significant higher correlations were observed between fresh mass weight and dry mass weight, dry weight of the stem and dry weight of leaves. The path coefficients showed that the direct effects of different explanatory variables on the dry mass weight were mostly low. More significant direct effects were obtained with fresh mass weight, stem dry weight and leaf dry weight, indicating that the fresh mass weight allows for the indirect selection for dry mass weight.

Keys words: Correlation, indirect selection, forage breeding.

Recebido para publicação em 31/05/2010 e aprovado em 29/07/2011

'Trabalho parcialmente financiado com recursos do CNPq e da Fapemig.

${ }^{2}$ Engenheiro-Agronômo, Doutor. Universidade Federal do Acre, Centro de Ciências Agrárias, Rodovia BR 364, 6637, Km 4, Distrito Industrial, 69915-900, Rio Branco, Acre, Brasil. vanderley-agro@ig.com.br*Autor para correspondência

${ }^{3}$ Engenheiros-Agrônomos, Doutores. Embrapa Gado de Leite, Rua Eugênio do Nascimento, 610, Dom Bosco, 36038-330, Juiz de Fora, Minas Gerais, Brasil. fausto@ cnpgl.embrapa.br, ledo@cnpgl.embrapa.br

${ }^{4}$ Engenheiro-Agrônomo, Doutor. Embrapa Pecuária Sul, Rodovia BR 153, Km 603, Caixa Postal 242, 96401-970, Bagé, Rio Grande do Sul, Brasil. mauricio.kopp@ @ppsul.embrapa.br 


\section{INTRODUÇÃO}

O melhoramento de forrageiras normalmente se baseia na mensuração de diferentes características, tais como produção de massa verde, altura e vigor das plantas, peso seco de forragem, de caule e de folhas. A medição de algumas destas características muitas vezes é difícil, demorada e pode aumentar os custos dos programas de melhoramento. Todavia, a existência de dependência ou relação entre algumas destas características pode ser útil para realização de seleção indireta (Souza Sobrinho et al., 2009).

A seleção de genótipos superiores em B. ruziziensis é comumente realizada utilizando-se a produtividade de matéria seca de folhas, em função de sua importância na produção animal (Euclides et al., 2000). Entretanto, a mensuração deste caráter é demorada por depender de processos de liofilização ou secagem em estufa. Uma maneira de acelerar o processo de seleção e eliminar medições demoradas é a seleção para caracteres fortemente correlacionados ao caráter de interesse e que sejam de fácil mensuração (Cruz et al., 2004). No caso das forrageiras, uma característica de fácil obtenção e medição é o peso verde. Entretanto, para que esta característica seja utilizada como base para a seleção, é necessário investigar possíveis associações dela com outras características consideradas na seleção.

Entender as relações entre caracteres de interesse para melhoramento de plantas é de grande importância, visto que a obtenção de ganhos genéticos e a classificação dos genótipos superiores são, em muitos casos, dirigidas conjuntamente (Cruz et al., 2004). Outra situação é aquela em que a seleção de determinados caracteres é dificultada em razão da baixa herdabilidade, de problemas na identificação e medição e, ainda, no caso em que a seleção para um caráter ocasiona redução em outro (Carvalho et al., 2001).

Estudos de correlações simples sejam fenotípicas, genotípicas e ambientais, apenas quantificam a relação entre variáveis ao pares, sem, contudo, considerar suas causas. Estudos mais detalhados sobre associações entre caracteres são realizados pela análise de trilha e por correlações parciais (Cruz et al., 2004). A análise de trilha é um procedimento que permite a decomposição das correlações em efeitos diretos e indiretos de um grupo de variáveis explicativas sobre uma variável básica de interesse, sendo de muita utilidade na seleção de genótipos para múltiplos caracteres em programas de melhoramento (Caierão et al., 2001; Coimbra et al., 2005).

Em estudos envolvendo grande número de variáveis é necessário uma investigação preliminar pormenorizada a fim de detectar a presença ou não da multicolinearidade na matriz de correlação. Uma vez detectada a presença desta, alguns procedimentos são recomendados a fim de minimizar seus efeitos (Belsley et al., 2004). Carvalho \& Cruz (1996) sugerem que a análise de trilha com colinearidade pode ser realizada com todas as variáveis adotando-se procedimento semelhante ao da análise de regressão em crista ou cumeeira, semelhantemente a proposta de Hoerl \& Kennard (1970). Detalhes matemáticos a esse respeito podem ser vistos em Carvalho \& Cruz (1996), Cruz \& Carneiro (2003) e Cruz (2006). O uso da análise de trilha com presença ou não de colinearidade têm sido descritos em culturas como arroz (Cargnin et al., 2010), trigo (Carvalho et al., 1999a), pimentão (Carvalho et al., 1999b), milho (Carvalho et al., 2001), aveia (Caierão et al., 2001), canola (Coimbra et al., 2005), batata-doce (Cavalcanti et al., 2006; Miranda et al., 1988), batata (Silva et al., 2007), mandioca (Gomes et al., 2007) e cana-de-açúcar (Ferreira et al., 2007), para a identificação das associações entre características. Em gramíneas forrageiras, mais especificamente na $B$. ruziziensis, não foram encontrados trabalhos focando este tipo de análise com as mesmas variáveis utilizadas neste estudo.

Ante o exposto, o objetivo deste trabalho foi estudar as associações entre algumas características morfo-agronômicas na seleção de genótipos de B. ruziziensis via correlações simples e análise de trilha.

\section{MATERIAL E MÉTODOS}

O experimento foi conduzido no Campo Experimental de Coronel Pacheco (MG), da Embrapa Gado de Leite. Foram avaliadas 118 progênies de meios-irmãos de $B$. ruziziensis obtidas por meio de intercruzamento natural de plantas selecionadas em pastagens implantadas há mais de 10 anos no Campo Experimental de Santa Mônica (Embrapa Gado de Leite - Valença/RJ). Como testemunhas foram utilizadas as cultivares Basilisk (B. decumbens), Marandu (B. brizantha), Comum (B. ruziziensis) e um acesso de $B$. spp.

O delineamento experimental foi o de blocos completos casualizados com duas repetições. Cada parcela foi constituída de uma linha de 3,0 m de comprimento, com espaçamentos de 1,0 m entre linhas e 0,5 m entre plantas. A partir de abril de 2006 foram realizados cortes com intervalos médios de 60 e 90 dias no período das águas e secas, respectivamente, tendo sido realizados sete cortes. Em cada um deles foram anotados dados referentes à altura $($ ALT - cm) e vigor (VIG - nota entre 1 e 5) das plantas, peso de massa verde (PMV - $\left.\mathrm{t} \mathrm{ha}^{-1}\right)$ e porcentagem de matéria seca da planta inteira (\%MSPI), do caule (\%MSC) e da folha (\%MSF), que foram utilizados para obtenção das estimativas de produtividade de matéria seca de forragem total (PMS - $\mathrm{t} \mathrm{ha}^{-1}$ ), de caule (PSC $-\mathrm{t} \mathrm{ha}^{-1}$ ), e de folha $\left(\mathrm{PSF}-\mathrm{t} \mathrm{ha}^{-1}\right)$ e relação entre produtividade de folha e caule (RFC). 
A matriz de correlação fenotípica entre os caracteres foi determinada a partir da análise de variância dos dados originais, utilizando-se o estimador do coeficiente de correlação de Pearson. As significâncias das estimativas das correlações foram verificadas pelo teste de Mantel (Cruz, 2006).

As correlações foram desdobradas pela análise de caminhamento ou trilha em estimativas dos efeitos diretos e indiretos, considerando-se o seguinte modelo estatístico: $y=p_{1} x_{1}+p_{2} x_{2}+\ldots+p_{n} x_{n}+p_{\varepsilon} u$, em que: $y$ : variável básica ou dependente produtividade de matéria seca; $\mathrm{x} 1$, $\mathrm{x} 2, \ldots, \mathrm{xn}$ : variáveis explicativas; $\mathrm{p}_{1}, \mathrm{p}_{2}, \ldots, \mathrm{p}_{\mathrm{n}}$ : coeficientes de trilha.

Os coeficientes de trilha foram estimados pelo seguinte sistema ( $\mathrm{Li}, 1975)$ :

$$
\left(\begin{array}{cccc}
1 & \mathbf{r}_{12} & \ldots & \mathbf{r}_{1 \mathrm{n}} \\
\mathbf{r}_{12} & \mathbf{1} & \ldots & \mathbf{r}_{2 \mathrm{n}} \\
\vdots & \vdots & \ddots & \vdots \\
\mathbf{r}_{1 \mathrm{n}} & \mathbf{r}_{2 \mathrm{n}} & \cdots & \mathbf{1}
\end{array}\right)\left(\begin{array}{l}
\mathbf{p}_{1} \\
\mathbf{p}_{2} \\
\vdots \\
\mathbf{p}_{\mathrm{n}}
\end{array}\right)=\left(\begin{array}{l}
\mathbf{r}_{1 \mathrm{y}} \\
\mathbf{r}_{2 \mathrm{y}} \\
\vdots \\
\mathbf{r}_{\mathrm{ny}}
\end{array}\right)
$$

Dessa maneira, a correlação entre a variável dependente e as explicativas $\left(\mathrm{r}_{\mathrm{xy}}\right)$, é dada por:

$$
\begin{aligned}
& r_{1 y}=p_{1}+p_{2} r_{12}+\ldots+p_{n} r_{1 n} \\
& r_{2 y}=p_{1} r_{12}+p_{2} \ldots+p_{n} r_{2 n} \\
& \ldots=\ldots \\
& r_{n y}=p_{1} r_{1 n}=p_{2} r_{2 n}+\ldots+p_{n}
\end{aligned}
$$

O coeficiente de determinação foi calculado por: $\mathrm{R}^{2}=\mathrm{p}_{1 \mathrm{y}}{ }^{2}+\mathrm{p}_{2 \mathrm{y}}{ }^{2}+\ldots 2 \mathrm{p}_{2 \mathrm{y}} \mathrm{p}_{2 \mathrm{n}} \mathrm{r}_{2 \mathrm{n}}$. Por sua vez. o coeficiente $\mathrm{p}_{\varepsilon}$ do efeito residual $\mathrm{u}$ foi determinado por: $\mathrm{p}_{\varepsilon}=\sqrt{\left(1-\mathrm{R}^{2}\right)^{\varepsilon}}$.

Realizou-se o diagnóstico de multicolinearidade nas variáveis explicativas, com base no número de condição (NC) estabelecido por Montgomery \& Peck (2001), sendo NC < 100 fraca (Não constitui problema sério); $100<\mathrm{NC}<1000$, moderada a forte e, $>1000$, severa. Com o efeito da multicolinearidade detectado, realizou-se a análise como sugerido por Carvalho \& Cruz (1996) e da maneira tradicional.

As análises seguiram as recomendações de Cruz (2006) e Cruz \& Carneiro (2003), sendo realizadas no aplicativo computacional Genes (Cruz, 2006).

\section{RESULTADOS E DISCUSSÃO}

Foi observado, inicialmente, a existência de variabilidade genética entre as progênies de de $B$. ruziziensis $(\mathrm{p}<0,001)$ para as características avaliadas. Essa condição é importante para exploração pormenorizada dos dados pela análise de trilha.

As estimativas dos coeficientes de correlação fenotípica entre as variáveis analisadas são apresentadas na Tabela 1. Verifica-se que os valores estimados para todas as correlações encontram-se dentro do espaço paramétrico (-1 a 1), indicando boa confiabilidade nos resultados (Resende, 2007). De modo geral, a magnitude das correlações entre os caracteres foi baixa. A altura de plantas mostrou-se correlacionada positivamente $(\mathrm{P}<0,01)$ com o vigor, produção de matéria verde e seca de forragem, além de produção de matéria seca de caule e de folhas. Por outro lado, apresentou associação negativa com a relação entre folhas e caules (RFC), ou seja, sugerindo que quanto maior a altura das plantas, menor a RFC. Em outras palavras, os resultados evidenciaram que quanto mais altas as plantas, proporcionalmente maior a quantidade de caules na forragem produzida (Tabela 1). Apesar da baixa magnitude, fica implícito que plantas mais alta poderão ter menos folhas (que são as fontes), comprometendo a quantidade de fotoassimilados, e por consequiência baixo armazenamento de reservas nos caules (drenos) e plantas menos nutritivas.

A \%MSPI apresentou associação positiva e significativa com as porcentagens de matéria seca de caule e folha. Embora a correlação com o PMV também tenha sido significativa e de baixa magnitude, esta foi negativa, exigindo atenção na seleção, pois o aumento em \%MSPI reduzirá PMV.

As maiores correlações positivas e significativas foram observadas para o PMV com o PMS, PSC e PSF e também para o PMS com o PSC e PSF, sempre superiores à 0,84 . Nas avaliações da produtividade de forragem, especialmente em etapas iniciais dos programas de melhoramento genético, quando o número de genótipos é grande, a obtenção da porcentagem de matéria seca e, consequentemente, produtividade de matéria seca, é difícil e onerosa. Além do mais, essas mensurações podem apresentar um erro elevado, considerando-se que muitas vezes as amostras para determinação da porcentagem de matéria seca são retiradas ao longo de um período do dia e posteriormente pesadas nos galpões de preparo de amostras, para posterior secagem em estufa. As diferenças entre o tempo que as amostras permaneceram no campo antes da pesagem podem influenciar grandemente nos resultados. Outras vezes, ainda, não há espaço suficiente nas estufas para secagem imediata das amostras. Estas são, então, armazenadas sob baixas temperaturas para posterior processamento, ou seja, obtenção de peso verde e seco (após secagem). Nesse caso, as diferenças entre as amostras que foram secas no mesmo dia da colheita e aquelas armazenadas também podem influenciar os resultados. Assim sendo, observa-se que a avaliação no campo considerando-se apenas o peso verde de forragem apresenta vantagens não somente operacionais, mas também de precisão e confiabilidade dos resultados. A mensuração da produtividade de forragem verde, com posterior descarte do material, agilizaria muito as avalia- 
Tabela 1. Estimativa dos coeficientes de correlação fenotípica entre dez caracteres de 122 genótipos (118 progênies de meios-irmãos de Brachiaria ruziziensis e quatro testemunhas), tomados dois a dois

\begin{tabular}{lccccccccc}
\hline Variáveis $^{1 /}$ & VIG & PMV & \%MSC & \%MSF & \%MSPI & PMS & RFC & PSC & PSF \\
\hline ALT & $0,7899^{* *}$ & $0,493^{* *}$ & 0,0598 & $-0,1678$ & $-0,0507$ & $0,4588^{* *}$ & $-0,2319^{* *}$ & $0,4619^{* *}$ & $0,3649^{* *}$ \\
VIG & & $0,5273^{* *}$ & $-0,0226$ & $-0,1771^{*}$ & $-0,1085$ & $0,4712^{* *}$ & $-0,1702$ & $0,4549^{* *}$ & $0,3983^{* *}$ \\
PMV & & & $-0,1653$ & $-0,2434^{* *}$ & $-0,2276^{* *}$ & $0,9257^{* *}$ & $-0,0169$ & $0,8437^{* *}$ & $0,8434^{* *}$ \\
\%MSC & & & & $0,3165^{* *}$ & $0,8295^{* *}$ & 0,1546 & $-0,5005^{* *}$ & 0,1662 & 0,1102 \\
\%MSF & & & & & $0,7722^{* *}$ & 0,0237 & 0,0482 & 0,0595 & $-0,0244$ \\
\%MSPI & & & & & & 0,1396 & $-0,2482 * *$ & 0,1607 & 0,0865 \\
PMS & & & & & & & $-0,1240$ & $0,9279^{* *}$ & $0,8911^{* *}$ \\
RFC & & & & & & & $-0,3883^{* *}$ & $0,2221^{*}$ \\
PSC & & & & & & & & $0,6575^{* *}$ \\
\hline
\end{tabular}

${ }^{1 / A L T ~(a l t u r a ~ d e ~ p l a n t a ~ e m ~} \mathrm{cm}$ ), VIG (vigor de planta dado em nota: 1 a 5), PMV (peso verde em $\mathrm{t} \mathrm{ha}^{-1}$ ), \%MSC (porcentagem de matéria seca de caule), \%MSF (porcentagem de matéria seca de folha), \%MSPI (porcentagem de matéria seca da planta inteira), PMS (produtividade de matéria seca em t ha ${ }^{-1}$ ), RFC (relação folha e caule), PSC (peso seco do caule em t ha ${ }^{-1}$ ), PSF (peso seco da folha em $\mathrm{t}^{-1}{ }^{-1}$ ).*, * significativo a 1 e $5 \%$ pelo teste de Mantel com 1000 simulações, respectivamente

Tabela 2. Efeitos diretos e indiretos das variáveis ${ }^{1 /}$ explicativas ALT, VIG e PMV sobre a variável básica peso seco total (PMS em $\left.\mathrm{t} \mathrm{ha}^{-1}\right)$, obtidas pelo método baseado na regressão em crista $(\mathrm{k}=0,0706)$ e pelo método tradicional

\begin{tabular}{|c|c|c|c|c|c|c|}
\hline \multirow[b]{2}{*}{ Variável } & \multirow[b]{2}{*}{ ALT } & & \multicolumn{2}{|c|}{ Regressão em crista } & \multirow{2}{*}{$\begin{array}{c}\text { Método } \\
\text { Efeito }\end{array}$} & \multirow{2}{*}{$\begin{array}{c}\text { Tradicional } \\
\text { VIF }\end{array}$} \\
\hline & & & Efeito & $\mathbf{V I F}^{2 \prime}$ & & \\
\hline & Efeito direto sobre & PMS & 0,001 & 2,5013 & $-0,0032$ & 2,882481 \\
\hline & Efeito indireto via & VIG & 0,003 & 1,3802 & $-0,0004$ & 1,838465 \\
\hline & Efeito indireto via & PMV & 0,1540 & 1,9929 & 0,0527 & 22,85243 \\
\hline & Efeito indireto via & $\% \mathrm{MSC}$ & 0,0020 & 0,0190 & 0,0012 & 0,196595 \\
\hline & Efeito indireto via & $\% \mathrm{MSF}$ & $-0,0040$ & 0,0900 & $-0,0004$ & 0,620677 \\
\hline & Efeito indireto via & $\%$ MSPI & $-0,0030$ & 0,0191 & $-0,0011$ & 0,220635 \\
\hline & Efeito indireto via & RFC & 0,0010 & 0,1565 & $-0,0030$ & 0,602222 \\
\hline & Efeito indireto via & PSC & 0,1824 & 1,1054 & 0,2573 & 7,354336 \\
\hline & Efeito indireto via & PSF & 0,1220 & 0,6732 & 0,1557 & 4,884678 \\
\hline & Total & & 0,4588 & & 0,4588 & \\
\hline \multirow[t]{11}{*}{ Variável } & VIG & & & & & \\
\hline & Efeito direto sobre & PMS & 0,0037 & 2,5355 & $-0,0005$ & 2,946731 \\
\hline & Efeito indireto via & ALT & 0,0008 & 1,3616 & $-0,0025$ & 1,79838 \\
\hline & Efeito indireto via & PMV & 0,1647 & 2,2799 & 0,0564 & 26,14393 \\
\hline & Efeito indireto via & $\% \mathrm{MSC}$ & $-0,0009$ & 0,0025 & $-0,0006$ & 0,027305 \\
\hline & Efeito indireto via & $\% \mathrm{MSF}$ & $-0,0040$ & 0,1002 & $-0,0004$ & 0,691108 \\
\hline & Efeito indireto via & $\%$ MSPI & $-0,0068$ & 0,0866 & $-0,0023$ & 1,001345 \\
\hline & Efeito indireto via & $\mathrm{RFC}$ & 0,0007 & 0,0844 & $-0,0022$ & 0,324618 \\
\hline & Efeito indireto via & PSC & 0,1796 & 1,0718 & 0,2534 & 7,130328 \\
\hline & Efeito indireto via & PSF & 0,1332 & 0,8016 & 0,1699 & 5,81614 \\
\hline & Total & & 0,4712 & & 0,4712 & \\
\hline \multirow[t]{11}{*}{ Variável } & PMV & & & & & \\
\hline & Efeito direto sobre & PMS & 0,3124 & 9,3997 & 0,1069 & 94,04292 \\
\hline & Efeito indireto via & ALT & 0,0005 & 0,5303 & $-0,0016$ & 0,700443 \\
\hline & Efeito indireto via & VIG & 0,0019 & 0,6150 & $-0,0003$ & 0,819191 \\
\hline & Efeito indireto via & $\% \mathrm{MSC}$ & $-0,006$ & 0,1364 & $-0,0034$ & 1,490844 \\
\hline & Efeito indireto via & $\% \mathrm{MSF}$ & $-0,005$ & 0,1889 & $-0,0006$ & 1,302981 \\
\hline & Efeito indireto via & $\%$ MSPI & $-0,014$ & 0,3804 & $-0,0049$ & 4,3957 \\
\hline & Efeito indireto via & RFC & 0,0001 & 0,0009 & $-0,0002$ & 0,0033 \\
\hline & Efeito indireto via & PSC & 0,3331 & 3,6873 & 0,4700 & 24,5304 \\
\hline & Efeito indireto via & PSF & 0,2820 & 3,5952 & 0,3598 & 26,0846 \\
\hline & Total & & 0,9257 & & 0,9257 & \\
\hline
\end{tabular}

${ }^{1}$ : ALT (altura de planta em cm), VIG (vigor de planta dado em nota: 1 a 5), PMV (peso verde em $\mathrm{t} \mathrm{ha}^{-1}$ ), \%MSC (porcentagem de caule), \%MSF (porcentagem de folha), \%MSPI (porcentagem da planta inteira), PMS (produtividade de matéria seca em $t_{\text {ha }}{ }^{-1}$ ), RFC (relação folha caule: peso de folhas dividido pelo peso de caule), PSC (peso seco do caule em t ha ${ }^{-1}$ ), PSF (peso seco da folha em $\mathrm{t} \mathrm{ha}^{-1}$ ).

2/: Variance inflation factor (saída da análise por default no programa Genes). 
ções, reduzindo custos e permitindo a avaliação de maior número de genótipos, contribuindo para aumentar as chances de identificação e seleção dos superiores (Ramalho et al., 2008; Cruz et al., 2004).

Embora normalmente utilizada como indicador de associação entre características as correlações, sejam fenotípicas, genotípicas ou ambientais, nem sempre evidenciam causa e efeito (Falconer, 1987). Neste contexto, a análise de trilha é uma técnica de grande utilidade, por evidenciar as verdadeiras correlações de causa e efeito (Cruz et al., 2004). Para que a avaliação da associação entre caracteres tenha uma estimativa e gere uma interpretação biologicamente apropriada e segura, é de funda- mental importância que se teste o grau de colinearidade entre as variáveis independentes (Coimbra et al., 2005).

Utilizando-se o PMS como variável dependente, detectou-se multicolinearidade moderada a forte entre as variáveis explicativas baseada na classificação proposta por Montgomery \& Peck (2001). Nesse caso, é aconselhável a eliminação das variáveis interrelacionadas (Rezende 2007) ou realizar a análise considerando-se os efeitos de colinearidade (Carvalho \& Cruz, 1996, Coimbra et al., 2005).

Problemas relativos à multicolinearidade já eram esperados, visto que estão envolvidos na análise alguns caracteres que são biologicamente dependentes, como, por exemplo, PMV, \%MSPI, \%MSC, \%MSF, PSC e PSF.

Tabela 3. Efeitos diretos e indiretos das variáveis ${ }^{1 /}$ explicativas \%MSC, \%MSF e \%MSPI sobre a variável básica peso seco total $\left(\mathrm{PMS}_{\mathrm{N}} \mathrm{em} \mathrm{th}^{-1}\right)$, obtidas pelo método baseado na regressão em crista $(\mathrm{k}=0,0706)$ e pelo método tradicional

\begin{tabular}{|c|c|c|c|c|c|c|}
\hline \multirow[b]{2}{*}{ Variável } & \multirow[b]{2}{*}{$\% \mathrm{MSC}$} & & \multicolumn{2}{|c|}{ Regressão em crista } & \multirow{2}{*}{\begin{tabular}{c|} 
Método \\
Efeito
\end{tabular}} & \multirow{2}{*}{$\begin{array}{l}\text { Tradicional } \\
\text { VIF }\end{array}$} \\
\hline & & & Efeito & $\mathbf{V I F}^{2 /}$ & & \\
\hline & Efeito direto sobre & PMS & 0,0397 & 5,7280 & 0,0205 & 54,6097 \\
\hline & Efeito indireto via & ALT & 0,0001 & 0,0078 & $-0,0002$ & 0,0104 \\
\hline & Efeito indireto via & VIG & $-0,000$ & 0,0011 & $1,2 \mathrm{E}-5$ & 0,0015 \\
\hline & Efeito indireto via & PMV & $-0,052$ & 0,2239 & $-0,0177$ & 2,5674 \\
\hline & Efeito indireto via & $\% \mathrm{MSF}$ & 0,0072 & 0,3198 & 0,0008 & 2,2054 \\
\hline & Efeito indireto via & $\%$ MSPI & 0,0520 & 5,0527 & 0,0179 & 58,3920 \\
\hline & Efeito indireto via & RFC & 0,0022 & 0,7288 & $-0,0064$ & 2,8040 \\
\hline & Efeito indireto via & PSC & 0,0656 & 0,1429 & 0,0926 & 0,9512 \\
\hline & Efeito indireto via & PSF & 0,0368 & 0,0611 & 0,0470 & 0,4437 \\
\hline & Total & & 0,1546 & & 0,1546 & \\
\hline \multirow[t]{11}{*}{ Variável } & $\%$ MSF & & & & & \\
\hline & Efeito direto sobre & PMS & 0,0228 & 3,6583 & 0,0025 & 22,0168 \\
\hline & Efeito indireto via & ALT & $-0,0002$ & 0,0611 & 0,0005 & 0,0813 \\
\hline & Efeito indireto via & VIG & $-0,0006$ & 0,0695 & 0,0001 & 0,0925 \\
\hline & Efeito indireto via & PMV & $-0,0760$ & 0,4855 & $-0,0260$ & 5,5673 \\
\hline & Efeito indireto via & $\% \mathrm{MSC}$ & 0,0126 & 0,5008 & 0,0065 & 5,4719 \\
\hline & Efeito indireto via & \%MSPI & 0,0484 & 4,3786 & 0,0167 & 50,6019 \\
\hline & Efeito indireto via & RFC & $-0,0002$ & 0,0067 & 0,0006 & 0,0257 \\
\hline & Efeito indireto via & PSC & 0,0235 & 0,0181 & 0,0331 & 0,1206 \\
\hline & Efeito indireto via & PSF & $-0,0081$ & 0,0030 &,- 0104 & 0,0220 \\
\hline & Total & & 0,0237 & & 0,0237 & \\
\hline \multirow[t]{11}{*}{ Variável } & $\% \%$ MSPI & & & & & \\
\hline & Efeito direto sobre & PMS & 0,0627 & 8,4160 & 0,0216 & 84,8598 \\
\hline & Efeito indireto via & ALT & $-0,00005$ & 0,0057 & 0,0002 & 0,0075 \\
\hline & Efeito indireto via & VIG & $-0,0004$ & 0,0261 & 0,0001 & 0,0348 \\
\hline & Efeito indireto via & PMV & $-0,0711$ & 0,4248 & $-0,0243$ & 4,8714 \\
\hline & Efeito indireto via & $\% \mathrm{MSC}$ & 0,0330 & 3,4389 & 0,0170 & 37,5769 \\
\hline & Efeito indireto via & $\% \mathrm{MSF}$ & 0,0176 & 1,9033 & 0,0019 & 13,1244 \\
\hline & Efeito indireto via & $\mathrm{RFC}$ & 0,0011 & 0,1792 & $-0,0032$ & 0,6895 \\
\hline & Efeito indireto via & PSC & 0,0634 & 0,1336 & 0,0895 & 0,8891 \\
\hline & Efeito indireto via & PSF & 0,0289 & 0,0379 & 0,0369 & 0,2750 \\
\hline & Total & & 0,1396 & & 0,1396 & \\
\hline
\end{tabular}

1: ALT (altura de planta em cm), VIG (vigor de planta dado em nota: 1 a 5), PMV (peso verde em t ha ${ }^{-1}$ ), \% MSC (porcentagem de caule), \%MSF (porcentagem de folha), \%MSPI (porcentagem da planta inteira), PMS (produtividade de matéria seca em $t$ ha ${ }^{-1}$ ), RFC (relação folha caule: peso de folhas dividido pelo peso de caule), PSC (peso seco do caule em t ha ${ }^{-1}$ ), PSF (peso seco da folha em $t \mathrm{ha}^{-1}$ ).

2/: Variance inflation factor (saída da análise por default no programa Genes). 
Os efeitos diretos e indiretos das variáveis explicativas sobre a variável básica (PMS) analisados sob colinearidade e pela forma tradicional são apresentados nas Tabelas 2 a 4. Observou-se que as estimativas dos coeficientes de determinação $\left(\mathrm{R}^{2}\right)$ pelas duas análises foram elevados (superiores à 0,97 ) (Tabela 4 ). O coeficiente de determinação ou explicação é um indicador para a análise do modelo adotado. No caso de $\mathrm{R}^{2}$ próximo ou igual à unidade (1), aceita-se que as variações na variável dependente são explicadas pelas variações das variáveis explicativas.
Dessa forma, para ambos os casos, verifica-se que as variações na PMS são devidas, em grande parte à PMV, PSC e PSF. A magnitude do coeficiente de determinação é superior a encontrada por Daher et al. (2004) em capimelefante, como também a de outras culturas como canola (Coimbra et al., 2005), bata-doce (Cavalcant et al., 2006), cana-de-açúcar (Ferreira et al., 2007 e Silva et al., 2009).

De modo geral, observa-se que os efeitos diretos das diferentes variáveis explicaram pouco da variação do PMS (Tabelas 2 a 4). Valores mais expressivos foram observa-

Tabela 4. Efeitos diretos e indiretos das variáveis ${ }^{1 /}$ explicativas RFC, PSC e PSF sobre a variável básica peso seco total (PMS em t $\left.\mathrm{ha}^{-1}\right)$, obtidas pelo método baseado na regressão em crista $(\mathrm{k}=0,0706)$ e pelo método tradicional

\begin{tabular}{|c|c|c|c|c|c|c|}
\hline \multirow[b]{2}{*}{ Variável } & \multirow[b]{2}{*}{ RFC } & & \multicolumn{2}{|c|}{ Regressão em crista } & \multirow{2}{*}{$\begin{array}{c}\text { Método } \\
\text { Efeito }\end{array}$} & \multirow{2}{*}{$\begin{array}{l}\text { Tradicional } \\
\text { VIF }\end{array}$} \\
\hline & & & Efeito & $\mathbf{V I F}^{2 /}$ & & \\
\hline & Efeito direto sobre & PMS & $-0,0043$ & 3,3350 & 0,0127 & 11,194 \\
\hline & Efeito indireto via & ALT & $-0,0002$ & 0,1174 & 0,0007 & 0,1551 \\
\hline & Efeito indireto via & VIG & $-0,0006$ & 0,0641 & 0,0001 & 0,0854 \\
\hline & Efeito indireto via & PMV & $-0,0053$ & 0,0025 & $-0,0018$ & 0,0282 \\
\hline & Efeito indireto via & $\% \mathrm{MSC}$ & $-0,0199$ & 1,2519 & $-0,0102$ & 13,6797 \\
\hline & Efeito indireto via & $\% \mathrm{MSF}$ & 0,0010 & 0,0073 & 0,0001 & 0,0506 \\
\hline & Efeito indireto via & $\%$ MSPI & $-0,0156$ & 0,4523 &,- 0054 & 5,2274 \\
\hline & Efeito indireto via & PSC & $-0,1533$ & 0,7812 &,- 2163 & 5,1968 \\
\hline & Efeito indireto via & PSF & 0,0743 & 0,2492 & 0,0947 & 1,8080 \\
\hline & Total & & $-0,124$ & & $-0,124$ & \\
\hline \multirow[t]{11}{*}{ Variável } & PSC & & & & & \\
\hline & Efeito direto sobre & PMS & 0,3948 & 5,9372 & 0,5571 & 34,4627 \\
\hline & Efeito indireto via & ALT & 0,0005 & 0,4657 & $-0,0016$ & 0,6151 \\
\hline & Efeito indireto via & VIG & 0,0017 & 0,4577 & $-0,0002$ & 0,6097 \\
\hline & Efeito indireto via & PMV & 0,2636 & 5,8376 & 0,0902 & 66,9397 \\
\hline & Efeito indireto via & $\% \mathrm{MSC}$ & 0,0066 & 0,1379 & 0,0034 & 1,5072 \\
\hline & Efeito indireto via & $\% \mathrm{MSF}$ & 0,0013 & 0,0112 & 0,0001 & 0,0770 \\
\hline & Efeito indireto via & $\%$ MSPI & 0,0100 & 0,1894 & 0,0035 & 2,1894 \\
\hline & Efeito indireto via & RFC & 0,0017 & 0,4388 & $-0,0049$ & 1,6880 \\
\hline & Efeito indireto via & PSF & 0,2198 & 2,1850 & 0,2805 & 15,8532 \\
\hline & Total & & 0,9279 & & & \\
\hline \multirow[t]{14}{*}{ Variável } & PSF & & & & & \\
\hline & Efeito direto sobre & PMS & 0,3344 & 5,7930 & 0,4266 & 36,6717 \\
\hline & Efeito indireto via & ALT & 0,0004 & 0,2907 & $-0,0012$ & 0,3839 \\
\hline & Efeito indireto via & VIG & 0,0015 & 0,3508 & $-0,0002$ & 0,4673 \\
\hline & Efeito indireto via & PMV & 0,2635 & 5,8335 & 0,0901 & 66,8927 \\
\hline & Efeito indireto via & $\% \mathrm{MSC}$ & 0,0044 & 0,0605 & 0,0022 & 0,66078 \\
\hline & Efeito indireto via & $\% \mathrm{MSF}$ & $-0,0005$ & 0,0019 & $-0,0001$ & 0,0132 \\
\hline & Efeito indireto via & $\%$ MSPI & 0,0054 & 0,0551 & 0,0019 & 0,6364 \\
\hline & Efeito indireto via & RFC & $-0,0010$ & 0,1434 & 0,0028 & 0,5518 \\
\hline & Efeito indireto via & PSC & 0,2596 & 2,2393 & 0,3663 & 14,8982 \\
\hline & Total & & 0,8911 & & 0,8911 & \\
\hline & $\mathrm{R}^{2}$ & & 0,9717 & & 0,999 & \\
\hline & Valor de $k$ na anális & & 0,0706 & & 0,0000 & \\
\hline & Efeito residual & & 0,1682 & & 0,0319 & \\
\hline
\end{tabular}

${ }^{1 /}$ : ALT (altura de planta em cm), VIG (vigor de planta dado em nota: 1 a 5), PMV (peso verde em t ha ${ }^{-1}$ ), \%MSC (porcentagem de caule), \% MSF (porcentagem de folha), \%MSPI (porcentagem da planta inteira), PMS (produtividade de matéria seca em t ha ${ }^{-1}$ ), RFC (relação folha caule: peso de folhas dividido pelo peso de caule), PSC (peso seco do caule em $\mathrm{t} \mathrm{ha}^{-1}$ ), PSF (peso seco da folha em $\mathrm{t}$ ha ${ }^{-1}$ ).

2/: Variance inflation factor (saída da análise por default no programa Genes). 
dos para PMV, PSC e PSF. Considerando-se, por exemplo, a altura das plantas, a correlação fenotípica observada entre ela e o PMS foi de 0,4588 , sendo significativa. Quando a colinearidade foi levada em conta, o efeito direto da altura das plantas no PMS caiu para 0,001 (Tabelas 1 e 2 a 4). Baixo efeito direto da altura de plantas no PMS também foi detectado por Daher et al. (2004) avaliando clones de capim-elefante. Em cana-de-açúcar a altura de plantas também apresentou baixo efeito sobre a variável básica tonelada de cana por hectare (Ferreira et al., 2007; Silva et al., 2009). Em aveia, Caierão et al. (2001) também verificaram baixa magnitude do efeito direto da estatura de plantas sobre a variável básica rendimento de grãos.

Assim como a altura de plantas, as variáveis vigor, \%MSC, \%MSF, \%MSPI e RFC (Tabelas 3 e 4) apresentaram efeitos diretos baixos, inclusive inferiores ao efeito residual $(0,1682)$, o que reduz a importância destas variáveis na seleção para PMS em B. ruziziensis. Por outro lado, as variáveis PMV, PSC e PSF apresentaram estimativas mais elevadas do seu efeito direto na PMS, superando os efeitos residuais (Tabelas 2 a 4). Embora tenha havido forte redução na magnitude das estimativas, quando comparadas às correlações fenotípicas, as mesmas mantiveram-se positivas e altas. Confirma-se, portanto, que o PMV, PSC e PSF contribuem efetivamente para explicar grande parte da variação no PMS, também confirmado pela estimativa do $\mathrm{R}^{2}$ (Vencovsky \& Barriga, 1992), permitindo seus empregos de forma segura para a seleção direta e indireta (Cruz et al., 2004) da produtividade de matéria seca de forragem dentro do programa de melhoramento genético de B. ruziziensis.

Considerando-se o PMV, que é uma das variáveis de mais fácil obtenção e avaliação, ressalta-se que a correlação fenotípica desta com o PMS $(0,9257)$ foi a segunda maior estimativa obtida entre as variáveis consideradas (Tabela 1). A análise de trilha, levando-se em conta a

Tabela 5. Efeito direto e indireto via outras variáveis ${ }^{1 /}$, da variável PMV, sem os efeitos das variáveis PSC e PSF, sobre PMS

\begin{tabular}{|c|c|c|}
\hline Variável PMV & Efeito & VIF \\
\hline Efeito Direto sobre PMS & 0,931288 & 1,527951 \\
\hline Efeito Indireto via ALT & 0,001658 & 0,530235 \\
\hline Efeito Indireto via VIG & 0,005945 & 0,612234 \\
\hline Efeito Indireto via \%MSC & $-0,02094$ & 0,116773 \\
\hline Efeito Indireto via \%MSF & $-0,01626$ & 0,184508 \\
\hline Efeito Indireto via \%MSPI & $-0,04182$ & 0,365187 \\
\hline Efeito Indireto via RFC & 0,00000 & 0,000395 \\
\hline Total & 0,9257 & \\
\hline \multicolumn{3}{|c|}{ 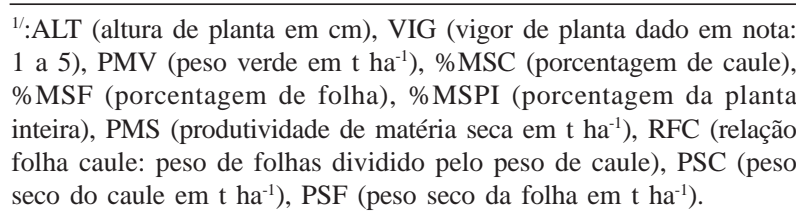 } \\
\hline
\end{tabular}

colinearidade entre as variáveis, confirmou o efeito direto do PMV no PMS, além de evidenciar efeitos indiretos de magnitudes semelhantes para PSC e PSF (Tabelas 2 a 4). Considerando-se que os pesos secos de caule e folha são derivados do PMV, associados aos respectivos percentuais de matéria seca do caule e folha, é provável que a retirada destas duas variáveis (PSC e PSF) das análises de trilha façam com que grande parte dos efeitos indiretos destas migre para a estimativa do efeito direto do PMV sobre o PMS. Assim, a magnitude das correlações obtidas pelas duas estimativas (fenotípica e trilha) seriam mais próximas, reforçando a associação entre o PMV e o PMS. Verificando a Tabela 5 onde consta apenas o efeito direto e indireto via altura, vigor, \%MSC, \%MSF, \%MSPI e RFC, da variável PMV, analisada sem os efeitos das variáveis PSC e PSF sobre PMS, confirma-se as afirmações anteriores.

Os resultados obtidos nesse trabalho confirmam a eficiência do PMV como seleção indireta para o PMS. Ainda assim, a necessidade de obtenção de amostras da porcentagem de matéria seca da forragem produzida, utilizadas para as estimativas do PMS, não está descartada. Eventualmente em alguns cortes durante algumas fases do melhoramento, principalmente, nas fases finais de avaliação dos genótipos, o PMS da forragem deverá ser considerado.

\section{CONCLUSÕES}

O peso de massa verde foi altamente correlacionado com peso de massa seca total, peso seco de caule e peso seco de folha.

A análise de trilha evidenciou efeito direto expressivo do peso de massa verde sobre o peso de matéria seca de forragem total.

O peso de massa verde pode ser utilizado diretamente para seleção de genótipos superiores.

\section{REFERÊNCIAS}

Belsley DA, Kuh E, \& Welsch R.E. (2004) Regression Diagnostics: identifying influential and sources of collinearity. New Jersey, Willey \& Sons. 314p

Cargnin A, Souza MA de, Pimentel AJB \& Fogaça CM (2010) Diversidade genética em cultivares de arroz e correlações entre caracteres agronômicos. Revista Ceres, 57:053-059.

Carvalho SP \& Cruz CD (1996) Diagnosis of multicollinearity: assesment of the condition of correlation matrices used in genetic studies. Brazilian Journal of Genetics, 19:479-484.

Carvalho SP, Cruz CD \& Carvalho CGP (1999a) Estimating gain by use of a classic selection under multicollinearity in wheat (Triticum aestivum). Genetics and Molecular Biology, 22:109113.

Carvalho CGP, Oliveira VR, Cruz CD \& Casali VWD (1999b) Análise de trilha sob multicolinearidade em pimentão. Pesquisa Agropecuária Brasileira, 34:603-613. 
Carvalho CGP, Borsato R, CRUZ CD \& Viana J.M.S (2001) Path analysis under multicollinearity in S0 x S0 maize hybrids. Crop Breeding and Applied Biotechnology, 1:263-270.

Caierão E, Carvalho FIF, Pacheco MT, Lonrecetti C, Marchioro VS \& Silva JG (2001) Seleção indireta em aveia para o incremento no rendimento de grãos. Ciência Rural, 31:231-236.

Cavalcanti JT, Ferreira PV, Soares L, Borges V, Silva PP \& Silva JW da (2006) Análise de trilha em caracteres de rendimento de clones de batata-doce (Sweet potato (L.) Lam.). Acta Scientiarum, 28:261-266.

Coimbra JLM, Benin G, Vieira EA, Oliveira AC, Carvalho FIF, Guidolin AF \& Soares, AP (2005) Conseqüências da multicolinearidade sobre a análise de trilha em canola. Ciência Rural, 35:347-352.

Cruz CD \& Carneiro PCS (2003) Modelos biométricos aplicados ao melhoramento genético. 2 ed. Viçosa, UFV. 579p.

Cruz CD, Regazzi AJ \& Carneiro PCS (2004) Modelos biométricos aplicados ao melhoramento genético 1. Viçosa, UFV. 480p.

Cruz CD (2006) Programa Genes: estatística experimental e matrizes. Viçosa, UFV. 285p.

Daher RF, Pereira AV, Lédo FJS, Amaral AT, Rocabado JMA, Ferreira CF \& Tardin FD (2004) Análise de trilha de caracteres forrageiros do capim-elefante (Pennisetum purpureum Schum.). Ciência Rural, 34:1531-1535.

Euclides VPB, Cardoso EG \& Macedo MCM (2000) Consumo voluntário de Brachiaria decumbens cv. Basilisk e Brachiaria brizantha cv. Marandu sob pastejo. Revista Brasileira de Zootecnia, 29:2200-2208, (Suplemento 2).

Falconer DS (1987) Introdução a genética quantitativa. Viçosa, UFV. 279 p.

Ferreira FM, Barros WS, Silva FL, Barbosa MHP, Cruz CD \& Bastos IT (2007) Relações fenotípicas e genotípicas entre componentes de produção em cana-de-açúcar. Bragantia, 66:605-610.
Gomes CN, Carvalho SP, Jesus MAS \& Custódio TN (2007) Caracterização morfoagronômica e coeficientes de trilha de caracteres componentes da produção em mandioca. Pesquisa Agropecuária Brasileira, 42:121-1130.

Hoerl AE \& Kennard RW (1970) Ridge regression: aplications to monorthogonal problems. Technometrics, 12:69-82.

Li CC (1975) Path analysis - a primer. 3 ed. Pacific Grove, The Boxwood. 347p.

Montgomery DC \& Peck EA (2001) Introduction to linear regression analysis. 3 ed. New York, John Wiley \& Sons. 504p.

Miranda JEC, Cruz CD \& Pereira AS (1988) Análise de trilha e divergência genética em cultivares e clones de batata-doce. Revista Brasileira de Genética, 11:881-892.

Ramalho MAP, Santos JB \& Pinto CABP (2008) Genética na Agropecuária. $4^{\mathrm{a}}$ ed. Lavras, UFLA. 463p.

Resende MDV (2007) Matemática e estatística na análise de experimentos e no melhoramento genético. Colombo, Embrapa Florestas. 561p.

Silva GO, Pereira AS, Souza VQ, Carvalho FIF \& Fritsche Neto R (2007) Correlações entre caracteres de aparência e rendimento e análise de trilha para aparência de batata. Bragantia, 66:381388 .

Silva FL, Pedrozo CA, Barbosa MHP, Resende MDV, Peternelli LA, Costa PMA \& Vieira MS (2009) Análise de trilha para componentes de produção de cana-de-açúcar via BLUP. Revista Ceres, 56:308-314.

Souza Sobrinho F, Lédo FJS, Kopp MM, Pereira AV \& Souza FF (2009) Melhoramento de gramíneas forrageiras na Embrapa Gado de Leite. In: VII Simpósio de Forragicultura e Pastagem, Lavras. Anais, UFLA. p.98-111

Vencovsky R \& Barriga P (1992) Genética biométrica no fitomelhoramento. Ribeirão Preto, Sociedade Brasileira de Genética. $496 \mathrm{p}$. 